\title{
Symmetric and Unsymmetric Balanced Incomplete Block Designs: A Comparative Analysis
}

\author{
Acha Chigozie Ke lechi \\ Department of Statistics, Michael Okpara University of Agriculture, Umudike, Abia State, Nigeria
}

\begin{abstract}
This paperdiscusses a comparative analysis on balanced incomplete block designs by using the classical analysis of variance (ANOVA) method. Fortunately, the data collected for the analysis were in two groups of the balanced incomplete-block designs (BIBD's), that is, symmetric, and unsymmetric (BIBD's). In this paper, the basic interest is to apply classical ANOVA on the two types of BIBD's and check whether they are significant and also minimizes error. A secondary data from N.R.C.R.I, Umudike, Abia State was used. To ach ieve this, we shall consider treatment (adjusted), block (adjusted) treatment (not adjusted) in the classical ANOVA method on the available data. Though, symmetric balanced incomplete block design (SBIBD) and unsymmetric balanced incomplete block design (USBIBD) are significant, it is pertinent to note that the SBIBD classical ANOVA method is found to be preferable to the USBIBD with reference to their variances at different level of significance.
\end{abstract}

Keywords Variance, Design, Experiment, Plot, Replication

\section{Introduction}

The basic concepts of the statistical design of experiments and data analysis were discovered in the early part of the $20^{\text {th }}$ century as a cost effective research design tool to help improve y ields in farming. Since then, many types of designs experiments and analysis techniques have been developed to meet the diverse needs of researchers and engineers. One of such experimental designs is called the balance incomplete block design (BIBD). Even though, there are missing data in $\mathrm{BIBD}$, it also possesses fine qualities, like having the ability to handle local control or minimize error. BIBDs can be used to eliminate block differences giving equal accuracy for comparing treatments. Also during the analysis of BIBD they are relatively less complicated than unbalanced designs.

To the best of my knowledge complete block design is widely used by researchers more than the balanced incomplete block designs because the missing data are computed before analysis. It is pertinent to note that, Classical ANOVA method can be used to analyzed BIBD without computing the missing data see, for example[1],[2],[3]. In this paper, the basic interest is on balanced incomplete design (BIBD's). Here, the Classical analysis-of-variance method was applied on SBIBD and USBIBD to check if they are significant. In addition, to know which of the BIBD's with minimal error.

* Corresponding author:

specialgozie@yahoo.com (Acha Chigozie Kelechi)

Published online at http://journal.sapub.org/statistics

Copyright (C) 2012 Scientific \& Academic Publishing. All Rights Reserved
The objective of this study is to check if there is any significance of the relationship between the variables at 0.01 and 0.05 levels with reference to minimum variance on symmetric balanced incomplete block design (SBIBD) and unsymmetric balanced inco mplete b lock design (USBIBD).

Hypothesis

$$
\text { Ho: } \mathrm{MSe}(\mathrm{SBIBD})=\mathrm{MSe}(\mathrm{USBIBD})
$$

where;

MSe $($ SBIBD $)=$ Mean square error for the SBIBD.

MSe $(U S B I B D)=$ Mean square error for the USBIBD.

\section{Literature}

A block design is a set together with a family of subsets (repeated subsets are allowed at times) whose members are chosen to satisfy some set of properties that are deemed useful for a particular application. These applications come from many areas, including experimental design, finite geometry, software testing, cryptography, and algebraic geometry. Many variations have been examined, but the most intensely studied are the balanced incomplete block designs (BIBDs or 2-designs) which historically were related to statistical issues in the design of experiments, see, hppt://en.wikipedia.org/wiki/Block_design[4],[5],[6].

A complete-block design is one of the most widely used designs. It is used when it is possible to run all the treatment combinations in each book. In situations where it is not possible to run all the treatment combinations in each book due to shortage of experimental apparatus or facilities or the physical size of the block, an incomplete-block design is 
used: see, for examp le,[7],[2]. A balanced incomp lete block design in which the number $\mathrm{b}$ of blocks equals the number $\mathrm{v}$ of elements arranged among the blocks is said to be symmetric, see www.answer.co m/topic / symmetric-designmathematics.

Some of the leading studies on balance incomplete block designs are [7],[8],[9],[10],[11],[12],[13] and[14]. However, this paper briefly discusses the balanced incomplete-block designs (BIBD's) and further analysis symmetric balanced incomplete block design (SBIBD) and unsymmetric balanced incomplete block design (USBIBD) with respect to their means. The Classical analysis-of-variance methods a statistical method for making simultaneous comparisons between two or more means. These methods were differently applied to data collected and were represented in various analysis-of-variance tables. The case study data employed here were obtained from the National Root Crops Research Institute (NRCRI) Umudike, Abia State, Nigeria. The data are on varieties of cassava with different ratios of Nitrogen, Phosphorous and potassium (NPK). The data are secondary data, whose entries are abinito arranged as BIBD by the experimenter.

\section{Preliminaries}

\subsection{Symmetric Balanced Incomplete-block Design}

Here, we assume that there are $t$ treatments and b blocks. In addition, we assume each block contains $\mathrm{k}$ treatment each of which occurs $r$ times in the design (or is replicated $r$ times), and that there are $\mathrm{N}=\operatorname{tr}=\mathrm{bk}$ total observations; see, for example [9]. Furthermore, the number of times each pair of treatments appears in the same block is

$$
\frac{\lambda=\gamma(\kappa-1)}{t-1}
$$

if $\mathrm{t}=\mathrm{b}$, the design is said to be symmetric. The para meter $\lambda$ must be an integer. The symmetry property of a design occur when the row effect and the column effects of the design are interchanged and still the error sum of squares so calculated in each remains the same, see, [2].

\subsection{Unsymmetric Bal anced Incomplete-bl ock Design}

we assume that there are $t$ treatments and $b$ blocks. The only difference between SBIBD and USBIBD is that $t \neq b$, the design is said to be unsymmetric.

a.The Classical Model: Some existing data sets are evaluated to see if they satis fy the assumption for application of chosen models. There are three conceptual classes of such models in designs:

-Fixed-effects models

-Random -effects models

-Mixed-effects models

In this work, fixed effects model is employed. The fixed effect model analysis of variance applies to situations in which the experimenter has subjected his experimental material to several treatments, each of which affects only the mean of the underly ing normal distribution of the "response variable", see, [15].

b. The classical ANOVA: In statistics, analysis of variance is a collection of statistical models and their associated procedures which compare means by splitting the overall observed variance into different parts see.[8].The analys is of variance for classical ANOVA is summarized in Table 1, Table 2 and Table 3.

Table 1. Analysis of variance for the balanced incomplete block design when treatment is adjusted

\begin{tabular}{|c|c|c|c|c|}
\hline Sources of variation & Sum of squares & Degree of freedom & Mean Square & $\mathrm{F}_{0}$ \\
\hline $\begin{array}{l}\text { Universal } \\
\text { Mean }\end{array}$ & $\frac{(Y)^{2}}{N}$ & 1 & - & \\
\hline Blocks & $k \sum Q_{i}^{2}$ & $t-1$ & $S S_{\text {Treatment (adjusted }}$ & $F=\frac{M S_{\text {Treatment (adjustment) }}}{}$ \\
\hline & $\lambda t$ & & $t-1$ & $M S_{E}$ \\
\hline Treatment & $\frac{\sum Y_{j}^{2}}{k}-\frac{Y^{2}}{N}$ & b-1 & $\frac{S S_{\text {Block }}}{b-1}$ & \\
\hline Error & $\mathrm{SS}_{\mathrm{E}}$ (by subtraction) & $\mathrm{N}-\mathrm{t}-\mathrm{b}-1$ & $\frac{S S_{E}}{N-t-b-1}$ & \\
\hline Total & $\sum_{i} \sum_{j}$ & $\mathrm{~N}$ & & \\
\hline
\end{tabular}


Table 2. Analysis of Variance for the balanced incomplete block design when treatment is not adjusted

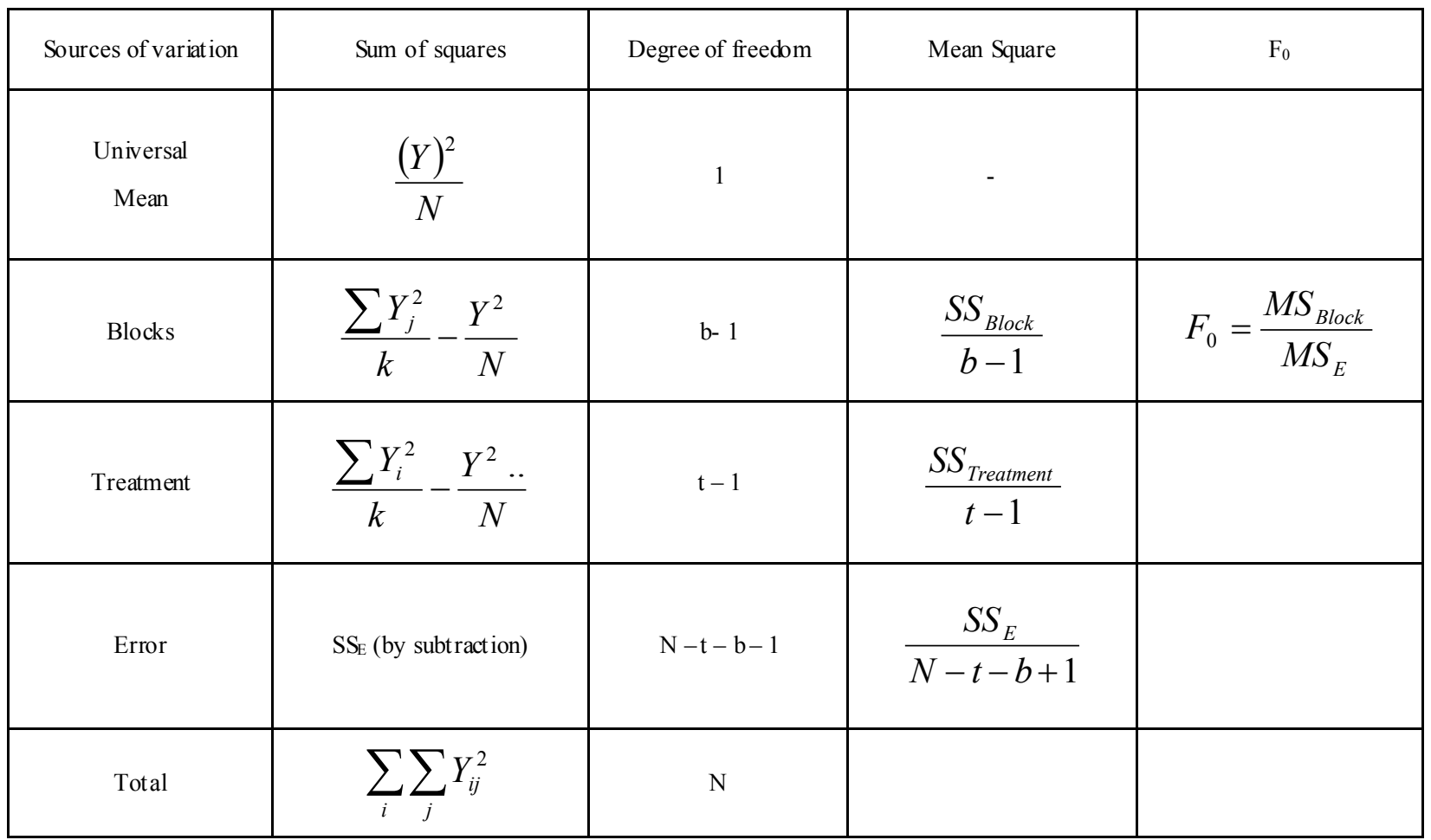

Source: Mont gomery (1976) Chapter 6.

Table 3. Analysis of Variance for the Balanced incomplete Block Design when Block is adjusted

\begin{tabular}{|c|c|c|c|c|}
\hline Sources of variation & Sum of squares & $\begin{array}{l}\text { Degree of } \\
\text { freedom }\end{array}$ & Mean Square & $\mathrm{F}_{0}$ \\
\hline $\begin{array}{c}\text { Universal } \\
\text { Mean }\end{array}$ & $\frac{(Y)^{2}}{N}$ & 1 & - & \\
\hline Blocks & $\frac{r \sum_{j=1}^{b}\left(Q_{j}^{i}\right)^{2}}{\lambda b}$ & b- 1 & $\frac{S S_{\text {Block(adjusted }}}{b-1}$ & $F_{o}=\frac{M S_{\text {Block(adjusted })}}{M S_{E}}$ \\
\hline Treatment & $\frac{\sum Y_{i}^{2}}{k}-\frac{Y^{2} \cdot .}{N}$ & $\mathrm{t}-1$ & $\frac{S S_{\text {Treatment }}}{t-1}$ & \\
\hline Error & $\mathrm{SS}_{\mathrm{E}}$ (by subtraction) & $\mathrm{N}-\mathrm{t}-\mathrm{b}-1$ & $\frac{S S_{E}}{N-t-b+1}$ & \\
\hline Total & $i \quad j$ & $\mathrm{~N}$ & & \\
\hline
\end{tabular}

Source: Montgomery (1976), Chapter 6.

\section{Experiment A}

A balanced incomplete-block design (BIBD) that is symmetric was used to study the yield on four varieties of cassava with four different rates of NPK. These rates were administered in addition to the natural manure. The data collected from the experiment are tabulated in the layout of table 4 . 
Table 4. Qualitative layout of the experiment A

\begin{tabular}{|c|c|c|c|}
\hline Block 1 & B & C & D \\
\hline Block 2 & A & C & D \\
\hline Block 3 & A & B \\
\hline Block 4 & A & B & D \\
\hline
\end{tabular}

Table 5. Raw data for the analysis of-variance for experiment $A$

\begin{tabular}{|c|c|c|c|c|c|}
\hline Block (cassava) & & & & & \\
\hline Treatment (fertilizer) & 1 & 2 & 3 & 4 & Yi \\
\hline 1 & 2 & & 20 & 7 & 49 \\
\hline 2 & & 32 & 14 & 3 & 48 \\
\hline 3 & 4 & 13 & 31 & & 34 \\
\hline 4 & 0 & 23 & & 11 & Y..(160) \\
\hline Yi & 6 & 68 & 65 & 21 & . \\
\hline
\end{tabular}

Source: NCRP under NRCRI Umudike (1992) entries sponsored by IFAD (world bank)

Table 6. analysis of variance when treatment is adjusted for experiment A

\begin{tabular}{|c|c|c|c|c|c|c|}
\hline Sources of variation & Sum of square & $\begin{array}{c}\text { Degrees of } \\
\text { freedom }\end{array}$ & Mean squares & F-ratio & $\begin{array}{c}\text { F-test at } \\
0.01\end{array}$ & $\begin{array}{c}\text { F-test at } \\
0.05\end{array}$ \\
\hline Universal mean & 2133.33 & 1 & & & & \\
\hline $\begin{array}{c}\text { Treatment } \\
\text { (adjusted) }\end{array}$ & 880.83 & 3 & 293.61 & 4.04 & 3.62 & 3.41 \\
\hline Block & 100.67 & 3 & 18.33 & & & \\
\hline Error & 363.17 & 5 & 72.63 & & & \\
\hline Total & 3478 & 12 & & & & \\
\hline
\end{tabular}

Since $\mathrm{F} c a l \quad \mathrm{Ftab}$ at different levels of probability, we conclude that the fertilizer applied has a significant effect on the cassava.

Table 7. Analaysis of variance when block is adjusted for Experiment A

\begin{tabular}{|c|c|c|c|}
\hline Sources of variation & Sum of squares & Degrees of freedom & Mean squares \\
\hline Universal mean & 2133.33 & 1 & \\
\hline Treatment & 975.34 & 3 & \\
\hline Blocks (adjusted) & 6.17 & 3 & 72.63 \\
\hline Error & 363.17 & 12 & \\
\hline Total & 3478 & & 5 \\
\hline
\end{tabular}

Table 8. Analysis of Variance when treatment is not adjusted for Experiment A

\begin{tabular}{|l|l|l|l|l|l|l|}
\hline $\begin{array}{l}\text { Sources of } \\
\text { Variation }\end{array}$ & $\begin{array}{l}\text { Sum of } \\
\text { Squares }\end{array}$ & $\begin{array}{l}\text { Degree of } \\
\text { freedom }\end{array}$ & $\begin{array}{l}\text { Mean } \\
\text { Square }\end{array}$ & F-ratio & $\begin{array}{l}\text { F-test } \\
0.01\end{array}$ & $\begin{array}{l}\text { F-test } \\
\text { at } 0.05\end{array}$ \\
\hline Universal mean & 2133.33 & 1 & & & & \\
\hline Treatment & 975.34 & 3 & 325.11 & 6.05 & 3.62 & 3.41 \\
\hline Blocks & 100.67 & 3 & & & & \\
\hline Error & 268.66 & 5 & 53.732 & & & \\
\hline Total & 3478 & 12 & & & & \\
\hline
\end{tabular}


The analysis of variance in Table 8 shows that $F_{c a l} \geq F_{t a b}$ at different levels of probability, we conclude that the fertilizer applied has a significant effect on the cassava.

\section{Experiment B}

Consider example 2, an unsymmetric balanced incomp lete block design (UBIBD) was used to study the yield in nine varieties of cassava with three different rates of NPK. These rates were administered in addition to the natural manure. The data collected from the experiment are tabulated in the layout of table 9 .
Table 9. Qualitative Layout of the Experiment B

\begin{tabular}{|c|c|c|}
\hline Block 1 & A & B \\
\hline Block 2 3 & B & C \\
\hline Block 3 & A & C \\
\hline Block 4 & A & B \\
\hline Block 5 & B & C \\
\hline Block 6 & A & B \\
\hline Block 7 & A & C \\
\hline Block 8 & B & C \\
\hline Block 9 & A & C \\
\hline
\end{tabular}

Notice that each pair of treatment in Table 9 (AB,AC.. ) occurs together twice 9in exactly 2 blocks)

Table 10. Raw data for the analysis of variance for experiment B

\begin{tabular}{|c|c|c|c|c|c|c|c|c|c|c|}
\hline & \multicolumn{9}{|c|}{ BLOCK } \\
\hline $\begin{array}{c}\text { TREAT } \\
\text { MENT }\end{array}$ & 1 & 2 & 3 & 4 & 5 & 6 & 7 & 8 & 9 & TOTAL \\
\hline 1 & 36 & & 33 & 34 & & 33 & 35 & & 35 & 206 \\
\hline 2 & 37 & 36 & & 36 & 36 & 35 & & 38 & & 218 \\
\hline 3 & & 34 & 34 & & 36 & & 33 & 34 & 35 & 206 \\
\hline TOTAL & 73 & 70 & 67 & 70 & 72 & 68 & 68 & 72 & 70 & 630 \\
\hline
\end{tabular}

Source: NCRP under NRCRI Umudike (1992) entries sponsored by IFAD (World Bank)

The analysis of variance when treatment is adjusted for Experiment 2 is show in Table 11.

Table 11. Analysis of variance when treatment is adjusted for Experiment B

\begin{tabular}{|c|c|c|c|c|c|c|}
\hline $\begin{array}{c}\text { Sources of } \\
\text { Variation }\end{array}$ & $\begin{array}{c}\text { Sum of } \\
\text { Squares }\end{array}$ & $\begin{array}{c}\text { Degree of } \\
\text { freedom }\end{array}$ & $\begin{array}{c}\text { Mean } \\
\text { Square }\end{array}$ & F-Cal & $\begin{array}{c}\text { F-test } \\
\text { at } 0.01\end{array}$ & $\begin{array}{c}\text { F-test } \\
\text { at } 0.05\end{array}$ \\
\hline Universal mean & 22050 & 1 & & & & \\
\hline Treatment & 10.33 & 2 & 5.165 & 5.42 & 3.26 & 4.74 \\
\hline Blocks & 17.00 & 8 & 2.125 & & & \\
\hline Error & 6.67 & 7 & 0.953 & & & \\
\hline Total & 22084.00 & 18 & & & & \\
\hline
\end{tabular}

Since $F_{c a l} \geq F_{t a b}$ at different levels of probability, we conclude that the fertilizer applied has a significant effect on the cassava.

Table 12. Analysis of variance when treatment is not adjusted for Experiment $B$

\begin{tabular}{|c|c|c|c|c|c|c|}
\hline $\begin{array}{c}\text { Sources of } \\
\text { Variation }\end{array}$ & $\begin{array}{c}\text { Sum of } \\
\text { Squares }\end{array}$ & $\begin{array}{c}\text { Degree of } \\
\text { freedom }\end{array}$ & $\begin{array}{c}\text { Mean } \\
\text { Square }\end{array}$ & F-Cal & $\begin{array}{c}\text { F-test at } \\
0.01\end{array}$ & $\begin{array}{c}\text { F-test } \\
\text { at } 0.05\end{array}$ \\
\hline Universal mean & 22050 & 1 & & & & \\
\hline Treatment & 16.00 & 2 & 8.00 & 57.14 & 3.26 & 4.74 \\
\hline Blocks & 17.00 & 8 & & & & \\
\hline Error & 1 & 7 & 0.14 & & & \\
\hline Total & 34.00 & 18 & & & & \\
\hline
\end{tabular}


Here $F_{c a l} \geq F_{t a b}$ at different levels of probability, we conclude that the fertilizer applied has a significant effect on the cassava.

Table 13. Analysis of variance when block is adjusted for Experiment B

\begin{tabular}{|c|c|c|c|}
\hline $\begin{array}{c}\text { Sources of } \\
\text { Variation }\end{array}$ & $\begin{array}{c}\text { Sum of } \\
\text { squares }\end{array}$ & $\begin{array}{c}\text { Degree of } \\
\text { freedom }\end{array}$ & $\begin{array}{c}\text { Mean } \\
\text { Square }\end{array}$ \\
\hline Universal mean & 22050 & 1 & \\
\hline Treatment & 16.00 & 2 & \\
\hline Blocks & 4.89 & 8 & \\
\hline Error & 13.11 & 7 & 6.11 \\
\hline Total & 22084.00 & 18 & \\
\hline
\end{tabular}

\section{Result Presentation}

The symmetric and unsymmetric balanced incomplete block designs (Experiment A\&B) are summarized in the table $14 \& 15$ below.

Table 14. Summarized results of the symmetric balanced incomplete block design

\begin{tabular}{|c|c|c|}
\hline & \multicolumn{2}{|c|}{ Experiment } \\
\hline & 0.05 & 0.01 \\
\hline $\begin{array}{c}\text { Treatments (Not } \\
\text { Adjusted) }\end{array}$ & Significant & Significant \\
\hline $\begin{array}{c}\text { Treatments } \\
\text { (Adjusted) }\end{array}$ & Significant & Significant \\
\hline
\end{tabular}

Table 15. Summarized results of the unsymmetric balanced incomplete block design

\begin{tabular}{|c|c|c|}
\hline & \multicolumn{2}{|c|}{ Experiment } \\
\hline & 0.05 & 0.01 \\
\hline $\begin{array}{c}\text { Treatments } \\
\text { (Not Adjusted) }\end{array}$ & Significant & Significant \\
\hline $\begin{array}{c}\text { Treatments } \\
\text { (Adjusted) }\end{array}$ & Significant & Significant \\
\hline
\end{tabular}

\section{Summary and Conclusions}

Considering the results obtained from the experiment used in this research work, different observation were made. In experiment 1 , that is, a symmetric balanced incomp lete block design (SBIBD), the classical ANOVA method, when treatments are not adjusted. Also when the treatments are adjusted using classical ANOVA method was significant at 0.05 and 0.01 levels of probability. However, the classical and vector space ANOVA methods were considered and found to be significant at 0.05 and 0.01 levels of probability. In summary the classical ANOVA was all significant at 0.05 and 0.01 levels of probability. On the basis of comparison, using minimization of error in BIBD, we have that SBIBD leads to a minimum error than USBIBD whether the treatment is adjusted or not. Also it is better to adjust the treatments in SBIBD and USBIBD because the adjustment leads to minimum error.

To have an effective comparis on of the two methods, the following observations were made:

( $i$ ) Based on minimization of error in BIBD, we have that SBIBD leads to a minimum error than USBIBD whether the treatment is adjusted or not.

(ii) When treatments are adjusted or not adjusted, the classical ANOVA method was applied on SBIBD and USBIBD; both yielded the same result, that is, both are significant at 0.05 and 0.01 levels of probability.

(iii) The classical ANOVA method on SBIBD seems easier and more convenient to handle than the classical ANOVA method on USBIBD.

(iv) Block is being adjusted to know if the treatment is SBIBD or USBIBD by checking whether the error sum of squares for the treatments when adjusted equals the error sum of squares for the blocks when adjusted.

\section{REFERENCES}

[1] Gomez. A.K. and Gomez, A.A. Statistical Procedures for Agricultural Research, John Wiley and Sons, Inc, new york, 1983.

[2] Montgomery, D.C. Design and Analysis of Experiments, John Wiley and sons, Inc, New York, 1976.

[3] Cochran, W.G. and Cox, G.M. Experimental designs, J. Wiley, New York, 1957.

[4] On-line Available: hppt://en.wikipedia.org/wiki/Block_ design accessed 6th June 2012.

[5] On-line Available: http://www.highbeam.com/doc/ 10106 -balanc einco mpletblckdsgn.html accessed 6th June 2012.

[6] Online Available: http://www.answer.com/topic/symmetricdesign-mathematics accessed 6th June 2012.

[7] Acha, C. K. Impact of Housing and Age of Birds on Egg Production. International Journal of Numerical Mathematics, vol.5, no.2, pp. $275-298,2010$.

[8] Bose, R. C. On the construction of balanced incomplete-block designs, annals of eugenics, vol.9, pp.353-399, 1939.

[9] Bose, R. C. A Note on Fishers inequality for balanced incomplete-block designs, Annal of Math.Stat. vol.20, pp.619-620, 1949.

[10] Bose, R.C. and Nair, K.R. Partially balanced incomplete-block designs, Ankhya, vol.4, pp.237-372, 1939.

[11] Fisher, R.A. An Examination of the Different Possible Solutions of a Problem in Incomplete-Blocks, Annals of Eugenics, vol.10, pp.52-75, 1940.

[12] Nair, K.R. and Rao, C.R. A Note on Partially Balanced Incomplete Block Designs, Science and Culture, vol.7, pp.568-569, 1942.

[13] Street, A.I. and street, D.J. Combinatories of Experimental Design, Oxford University Press, Oxford, 1987. 
[14] Yates, F. Incomplete Randomized Blocks, Annals of Eugenics, vol.7, pp.121-140, 1936.
[15] Hill D.H and Williams W.C. The America heritage dictionary of the English language, file://A:/ Analysis of Variance: Definition and Much More From Answer Com.Htm, 2005. 